ORIGINAL ARTICLE

\title{
Acute effects of a single open sea air dive and post-dive posture on cardiac output and pulmonary gas exchange in recreational divers
}

\author{
Z Dujic, D Bakovic, I Marinovic-Terzic, D Eterovic
}

Br J Sports Med 2005;39:e24 (http://www.bjsportmed.com/cgi/content/full/39/5/e24). doi: 10.1136/bjsm.2004.014308

See end of article for authors' affiliations

.....................

Correspondence to: Dr Dujic, School of Medicine, University of Split, Soltanska 2, Split 21000, Croatia; zdujic@bsb.mefst.hr

Accepted 27 September 2004
Objective: To evaluate the cardiopulmonary effects of open sea scuba air diving to $39 \mathrm{~m}$ (30 minutes bottom time) with standard decompression. To account for possible gravity dependent effects of venous gas bubbles, the variables were measured in different post-dive body postures and compared with the baseline values before the dive in the same posture.

Methods: Eight male divers conducted two similar dives on successive days. Their posture before and after the dive was either sitting or supine, in random order. The divers were evaluated before and 30,60, and 90 minutes after the dive. Venous bubbles were detected by precordial Doppler after the dive in four divers in the supine posture and two divers in the sitting posture.

Results: Arterialised oxygen tension had decreased at all times after the dive $(-11.3 \mathrm{~mm} \mathrm{Hg}, \mathrm{p}=$ 0.00006 ), due to decreased alveolar oxygen tension, irrespective of posture. Apart from an increase in the sitting posture 30 minutes after the dive, pulmonary capacity for carbon monoxide diffusion and cardiac index decreased, mostly 60 minutes after the dive $(-9 \%, p=0.0003$ and $-20 \%, p=0.0002$ respectively). The decrease in cardiac index was greater in the supine posture $(p=0.0004)$, and the physiological dead space/tidal volume ratio increased more in the sitting position ( $p=0.006$ ).

Conclusions: Field dives are associated with moderate impairments in cardiac output and gas exchange. Some of these impairments appear to depend on the posture of the diver after the dive.
W e have previously reported that air dry dives to $45 \mathrm{~m}$ (25 minutes bottom time) are associated with acute, transient reductions in pulmonary diffusing capacity for $\mathrm{CO}$ (CO transfer factor (TLCO)) and arterial oxygen saturation $\left(\mathrm{SaO}_{2}\right){ }^{1}$ The maximal decrease in TLco was $15 \%$ 40 minutes after the dive. Thorsen et al ${ }^{2}$ confirmed these results, reporting, however, smaller TLCO reductions after a dry dive to $39 \mathrm{~m}$. A later study observed post-dive decreases in dynamic lung flows and volumes. ${ }^{3}$ Both dry and wet (open sea) dives are associated with hyperoxia, increased density of breathing gas, and decompression stress with possible formation of venous bubbles and subsequent lung microembolisation (venous gas microemboli (VGM)). However, in open sea bounce dives there is also immersion, the mechanical load of the breathing apparatus, a greater level of physical activity, and exposure to a cold environment. Immersion in cold seawater results in breathing of colder and denser gas and may also, by inducing peripheral cutaneous vasoconstriction in conjunction with the immersion effect, potentiate greater central pooling of blood than in dry dives. Most previous studies on pulmonary function after open sea dives investigated professional, saturation dives, ${ }^{24-7}$ focusing on the effects observed days, weeks, and years after the dives. In contrast, Skogstad et al ${ }^{8}$ measured pulmonary function two hours after open sea bounce air dives to 10 and $50 \mathrm{~m}$. They reported similar reductions in TLCo (11-13\%) in both dives, in conjunction with spirometric decrements. In this study it was our intention to evaluate the acute effects of open sea air diving on pulmonary function, including hitherto unknown effects on cardiac output and physiological dead space, as an index of the degree of VGM. As apicobasal pulmonary distribution of VGM is in part gravity dependent, ${ }^{9}$ we also evaluated the possible impact of post-dive posture on the variables. To isolate the possible effects of gravity dependent VGM from the well known cardiopulmonary effects of body posture, measurements after a dive were compared with measurements before the dive in the same body position.

\section{METHODS}

Subjects and dive profiles

All the experimental procedures complied with the Declaration of Helsinki and the American Physiological Association's Ethical principles in the conduct of research with human participants and were approved by the School of Medicine Ethics Committee. Written informed consent was obtained from all the subjects, and their annual diving insurance was paid in exchange for their participation.

Eight male recreational divers, medically fit to dive based on the annual medical examination, with no clinical signs of cardiopulmonary disease, were included in the study. Their mean (SEM) age was 31.6 (2.1) years (range 24-40), height $181.6(2.1) \mathrm{cm}$ (range 172-191), and weight 86.1 (5.7) kg (range 63-110). Two subjects were smokers. All subjects were recreational divers, experienced only in compressed air diving with an average maximal depth of dive 62.5 (4.9) $\mathrm{m}$ (range 40-89) and diving experience 964.3 (352.4) hours (range 250-3000); none had ever performed saturation dives. As $40 \mathrm{~m}$ was the maximum allowed depth for these subjects, we chose a depth of $39 \mathrm{~m}$. The bottom time was 30 minutes, and

Abbreviations: $\mathrm{A}-\mathrm{aDO}_{2}$, alveolar-arterial $\mathrm{O}_{2}$ tension difference; $\mathrm{Cl}$, cardiac index; $F E V_{1}$, forced expired volume in one second; FVC, forced vital capacity; $\mathrm{PETO}_{2}$, partial pressure of end tidal $\mathrm{O}_{2} ; \mathrm{PETCO}_{2}$, partial pressure of end tidal $\mathrm{CO}_{2} ; \mathrm{PaO}_{2}$, arterial partial pressure of $\mathrm{O}_{2} ; \mathrm{PaCO}_{2}$, arterial partial pressure of $\mathrm{CO}_{2} ; \dot{\mathrm{Q}}$, pulmonary cardiac output; $\mathrm{SaO}_{2}$, arterial $\mathrm{O}_{2}$ saturation; $\mathrm{SV}$, stroke volume; $\mathrm{SVR}$, systemic vascular resistance; TLCO, CO transfer factor (pulmonary diffusing capacity for $\mathrm{CO})$; $\mathrm{VA}_{\mathrm{A}}$ alveolar volume; $\mathrm{VD}$, physiological dead space; $\mathrm{V}_{2}$, oxygen uptake; $\mathrm{VCO}_{2}$, carbon dioxide output; $\mathrm{VT}$, tidal volume; $\dot{\mathrm{VA}}$, alveolar ventilation; VGM, venous gas microemboli 
the ascent rate up to the first decompression stop was $18 \mathrm{~m} /$ min. The divers swam along a line in open sea to the $39 \mathrm{~m}$ mark. At the bottom, divers swam slowly mainly in the prone position. The first decompression stop was at $6 \mathrm{~m}$ for three minutes, and the second one at $3 \mathrm{~m}$ for 18 minutes. The depths of the decompression stops were marked on the line. The divers used air as breathing gas and measured the diving profile with a diving computer (Aladin Pro; Uwatec, Hallwil, Switzerland). Data on the dive profiles were downloaded from the diving computer on to a PC with data acquisition software. The subjects used wet suits. During the dive, subjects performed no exercise other than slow swimming. Smoking was prohibited at least 12 hours before the experiment. The sea temperature at the surface was 19$21{ }^{\circ} \mathrm{C}$, and on the bottom it was $14-15^{\circ} \mathrm{C}$. The dives were conducted at the village of Pisak, where steep underwater terrain allowed them to be performed only $30 \mathrm{~m}$ from the shoreline. This enabled us to test divers shortly after the end of the dives in a nearby house. The divers were not allowed to drink after a dive during the period of evaluation.

\section{Study protocol}

The dives took place on two consecutive days. Each diver performed two similar dives, with measurements of cardiopulmonary variables and Doppler bubble grade before and 30, 60 , and 90 minutes after a dive in the seated or supine position, in random order. Baseline measurements were obtained after the subject had relaxed seated or lying supine for a minimum of 20 minutes. The parameters of basal ventilation were then recorded for five minutes and averaged over the last two minutes. Other baseline measurements followed. The time difference between the two dives was 24 (2) hours.

\section{Doppler bubble monitoring}

Venous bubbles were detected using a continuous wave Doppler apparatus TSI model 9008 (Techno Scientific Inc, Concord, Ontario, Canada) equipped with a $2.5 \mathrm{MHz}$ precordial probe. The Spencer Doppler Scale ${ }^{10}$ with five grades was used: grade 0 , no bubbles; grade I, an occasional bubble with most cardiac cycles free of bubbles; grade II, many but less than half of the cardiac cycles contain bubbles; grade III, bubbles in most of the cardiac cycles but not obscuring heart sounds; grade IV, numerous bubbles obscuring heart sounds. For the precordial monitoring, recording was performed for one minute after the heart rate had stabilised to a resting rate. It was performed after a deep knee bend in the sitting posture and without it in the supine posture. The signals were assessed aurally and recorded on tape (Sony TCM-40DV) and graded in a blind manner by two trained investigators (DB and IM-T).

\section{Dead space}

The physiological dead space $(\mathrm{VD})$ was determined from the Bohr equation by using arterialised $\mathrm{PCO}_{2}\left(\mathrm{PaCO}_{2}\right)$ and mixed

Table 1 Cardiopulmonary variables in the sitting posture in eight male recreational divers before and 30,60, and 90 minutes after the dive

\begin{tabular}{|c|c|c|c|c|}
\hline Variable & Baseline & 30 & 60 & 90 \\
\hline \multicolumn{5}{|l|}{ Ventilation } \\
\hline$\dot{\mathrm{V}} \mathrm{E}(\mathrm{l} / \mathrm{min})$ & $10.4(0.78)$ & $11.6(1.13)$ & $9(1.59)$ & $10.1(0.81)$ \\
\hline$\dot{\mathrm{V}}_{\mathrm{A}}(\mathrm{l} / \mathrm{min})$ & $8.94(0.64)$ & $9.4(0.88)$ & $7.6(0.67)$ & $8.2(0.67)$ \\
\hline$V_{T}(\mathrm{ml})$ & $786(57.9)$ & $817(152)$ & $745(62)$ & $704(51.3)$ \\
\hline $\mathrm{fb}$ (breaths/min) & $13.5(0.95)$ & $15.5(1.45)$ & $13.9(1.06)$ & $14.7(1.38)$ \\
\hline $\mathrm{VD}_{\mathrm{D}} / \mathrm{V}_{\mathrm{T}}$ & $0.16(0.01)$ & $0.22(0.02)^{*}$ & $0.29(0.02)^{*}$ & $0.22(0.02)^{*}$ \\
\hline \multicolumn{5}{|l|}{ Spirometry and TLCO } \\
\hline $\mathrm{TLCO}(\mathrm{ml} / \mathrm{min} / \mathrm{mm} \mathrm{Hg})$ & $33.8(1.5)$ & $35.5(1.7)^{*}$ & $31.5(1.3)^{\star *}$ & $30.7(0.9)^{*}$ \\
\hline $\mathrm{TLCO} / \mathrm{VA}(\mathrm{ml} / \mathrm{min} / \mathrm{mm} \mathrm{Hg})$ & $4.6(0.2)$ & $4.8(0.2)^{*}$ & $4.3(0.2)^{* *}$ & $4.2(0.1)^{* *}$ \\
\hline FVC (litres) & $5.8(0.9)$ & $5.6(0.9)$ & $5.6(0.9)$ & $5.7(1.0)$ \\
\hline $\mathrm{FEV}_{1}$ (litres) & $4.6(0.7)$ & $4.6(0.7)$ & $4.6(0.8)$ & $4.6(0.8)$ \\
\hline $\mathrm{FEF}_{25-75 \%}(\mathrm{l} / \mathrm{s})$ & $4.5(0.3)$ & $4.5(0.3)$ & $4.5(0.3)$ & $4.5(0.3)$ \\
\hline \multicolumn{5}{|l|}{ Gas exchange } \\
\hline $\mathrm{PETO}_{2}(\mathrm{~mm} \mathrm{Hg})$ & $96.3(1.6)$ & $90.5(2.4)$ & $82.0(3.0)^{*}$ & $84.1(2.9)$ \\
\hline $\mathrm{PETCO}_{2}(\mathrm{~mm} \mathrm{Hg})$ & $35.4(0.6)$ & $33.8(0.8)^{*}$ & $34.1(0.8)$ & $36.0(0.7)$ \\
\hline $\mathrm{V}_{2}(\mathrm{ml} / \mathrm{min})$ & 427 (35.7) & $496(46.3)$ & 485 (31.1) & 464 (19.0) \\
\hline $\mathrm{V} \mathrm{O}_{2}(\mathrm{ml} / \mathrm{min})$ & 361 (27.2) & $408(44.9)$ & $352(21.9)$ & 345 (19.8) \\
\hline$R Q$ & $0.85(0.04)$ & $0.82(0.04)$ & $0.73(0.04)^{*}$ & $0.75(0.05)^{*}$ \\
\hline$\dot{\mathrm{V}}_{2} / \dot{\mathrm{V}}_{\mathrm{A}}$ & $47.7(6.1)$ & $53.1(8.9)$ & $64.9(6.1)^{*}$ & $57.9(6.9)^{*}$ \\
\hline $\mathrm{PaO}_{2}(\mathrm{~mm} \mathrm{Hg})$ & $89.0(2.4)$ & $80.0(2.7)^{\star *}$ & $73.4(1.6)^{\star *}$ & $78.9(2.8)^{*}$ \\
\hline $\mathrm{PaCO}_{2}(\mathrm{~mm} \mathrm{Hg})$ & $37.3(0.5)$ & $37.2(0.3)$ & $37.6(0.4)$ & $37.9(0.5)$ \\
\hline $\mathrm{SaO}_{2}(\%)$ & $98.6(0.4)$ & $97.8(0.4)$ & $97.1(0.6)$ & $96.4(0.5)^{\star *}$ \\
\hline $\mathrm{A}-\mathrm{aDO}_{2}(\mathrm{~mm} \mathrm{Hg})$ & $7.3(2.2)$ & $10.5(3.5)$ & $8.6(3.5)$ & $5.3(2.2)$ \\
\hline PCV & $0.43(0.2)$ & $0.44(0.05)$ & $0.43(0.05)$ & $0.43(0.03)$ \\
\hline $\mathrm{Hb}(\mathrm{g} / \mathrm{l})$ & $148.20(8.9)$ & $152.60(9.7)$ & $149.10(8.8)$ & $148.30(9.9)$ \\
\hline \multicolumn{5}{|l|}{ Cardiovascular } \\
\hline $\mathrm{SBP}(\mathrm{mm} \mathrm{Hg})$ & $131.1(2.2)$ & $138.5(2.1)^{\star *}$ & $118.1(3.2)^{\star *}$ & $119.1(2.1)^{\star *}$ \\
\hline $\mathrm{DBP}(\mathrm{mm} \mathrm{Hg})$ & $71.8(2.3)$ & $75(2.9)$ & $72.9(2.0)$ & $71.9(2.2)$ \\
\hline MAP $(\mathrm{mm} \mathrm{Hg})$ & $91.5(1.87)$ & $96.2(1.98)$ & $88(2.02)$ & $87.6(2.02)$ \\
\hline $\mathrm{Cl}\left(\mathrm{l} / \mathrm{min} / \mathrm{m}^{2}\right)$ & $3.0(0.2)$ & $3.4(0.4)^{*}$ & $2.5(0.2)^{* *}$ & $2.7(0.3)$ \\
\hline $\mathrm{SV}(\mathrm{ml})$ & $80.7(5.7)$ & $88.6(8.0)$ & $70.8(7.2)$ & $71.6(6.3)^{*}$ \\
\hline HR (beats/min) & 75.1 (3.4) & $78.3(3.4)$ & $72.6(2.7)$ & $76.3(2.1)$ \\
\hline SVR (mm Hg/l/min) & $15.6(0.9)$ & $14.9(1.4)$ & $18.7(2.3)$ & $17.2(1.7)$ \\
\hline \multicolumn{5}{|c|}{ 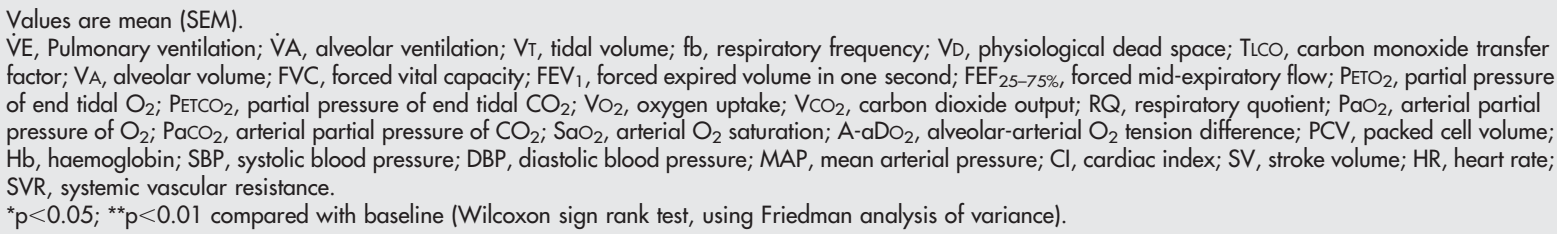 } \\
\hline
\end{tabular}


expired $\mathrm{CO}_{2}$. The effective alveolar ventilation $\left(\dot{\mathrm{V}}_{\mathrm{A}}\right)$ was calculated from the following equation:

$$
\left(\mathrm{VT}_{\mathrm{T}}-\mathrm{VD}_{\mathrm{D}}\right) \times \text { breathing frequency }(\mathrm{fb}) \text {. }
$$

Alveolar-arterial $\mathrm{O}_{2}$ difference $\left(\mathrm{A}-\mathrm{aDO}_{2}\right)$ was calculated as the difference between end tidal oxygen tension $\left(\mathrm{PeTO}_{2}\right)$ and arterialised oxygen tension $\left(\mathrm{PaO}_{2}\right)$. The anatomical dead space was estimated by the Fowler method, from the tidal volume (VT) and the end tidal and mixed expired $\mathrm{CO}_{2}$.

\section{Arterialised blood gas measurements}

$\mathrm{SaO}_{2}$ was measured with a pulse oximeter with earlobe probe (Dash 2000, GE Healthcare, Milwaukee, Wisconsin, USA), and arterialised (Finalgon Cream, Boehringer, Mannheim, Germany) earlobe blood samples were analysed immediately after collection on an IL 1620 analyser (Instrumentation Laboratory, Lexington, MA, USA) for standard blood gas variables. Packed cell volume was measured with a microcapillary centrifugation system.

\section{Measurements of pulmonary function}

Pulmonary function testing consisted of spirometry, measurement of basal ventilation, and single breath TLco. The measurements were performed by DB and IM-T, using the same equipment before and after a dive.

For spirometric tests, after inhaling their vital capacity, subjects performed forced maximal expiration. Three satisfactory manoeuvres were collected each time. The instrument used was the computerised Quark PFT (Cosmed, Rome, Italy). It was calibrated daily: $(a)$ volume calibration with a 3 litre hand pump; $(b)$ automatic checking of the proper gas mixture for TLCO measurements. Forced vital capacity (FVC), forced expired volume in one second $\left(\mathrm{FEV}_{1}\right)$, and peak expiratory flow rate were taken as the highest readings obtained. The maximal expiratory flow rates at $75 \%, 50 \%$, and $25 \%$ of FVC expired and mid-expiratory flow rate were taken from the best test defined by the highest sum of FVC and $\mathrm{FEV}_{1} \cdot{ }^{11}$

\section{Ventilatory measurements}

Ventilatory variables were collected continuously on a breath by breath basis (Cosmed Quark b2) with mask breathing, with interruptions when other measurements were performed. The measurements at each predefined time were obtained as two minute averages around that time. The Quark b2 uses ultrafast analysers for $\mathrm{CO}_{2}$ (infrared analyser) and $\mathrm{O}_{2}$ (zirconium heated analyser). The analysers were calibrated daily with a calibrating gas mixture composed of $5 \% \mathrm{CO}_{2}, 16 \% \mathrm{O}_{2}$, and the balance $\mathrm{N}_{2}$, and the flowmeter was calibrated with a 3 litre calibration syringe. Oxygen uptake $\left(\dot{\mathrm{V}}_{2}\right)$ and carbon dioxide output $\left(\dot{\mathrm{V}}_{\mathrm{CO}_{2}}\right)$ were determined from the continuous measurement of the concentrations of $\mathrm{CO}_{2}$ and $\mathrm{O}_{2}$ in the inspired and expired gas.

\section{TLCO measurements}

TLCO was determined by the single breath method, which requires the subjects to make maximal inspiration from the

\begin{tabular}{|c|c|c|c|c|}
\hline Variable & Baseline & 30 & 60 & 90 \\
\hline \multicolumn{5}{|l|}{ Ventilation } \\
\hline$\dot{V} E(I / \mathrm{min})$ & $9.5(0.74)$ & $11.5(0.74)$ & $9.5(0.74)$ & $9.1(0.42)$ \\
\hline$\dot{\mathrm{V}}_{\mathrm{A}}(\mathrm{l} / \mathrm{min})$ & $8.3(0.57)$ & $9.3(0.46)$ & $7.8(0.6)$ & $7.2(0.39)$ \\
\hline $\mathrm{V}_{T}(\mathrm{ml})$ & $768(60.5)$ & $762(71.1)$ & $768(91.2)$ & $670(51.3)$ \\
\hline $\mathrm{fb}$ (breaths/min) & $13.1(1.13)$ & $15.7(1.2)$ & $13.4(1.2)$ & $14.2(1.3)$ \\
\hline $\mathrm{VD}_{\mathrm{V}} / \mathrm{V}_{\mathrm{T}}$ & $0.16(0.01)$ & $0.22(0.02)^{*}$ & $0.23(0.02)^{*}$ & $0.25(0.01)^{*}$ \\
\hline \multicolumn{5}{|l|}{ Spirometry and TLCO } \\
\hline TLCO $(\mathrm{ml} / \mathrm{min} / \mathrm{mm} \mathrm{Hg})$ & $37.8(2.1)$ & $36.7(2.1)^{*}$ & $35.7(1.4)^{\star \star}$ & $34.1(1.7)$ \\
\hline $\mathrm{TLCO} / \mathrm{VA}_{\mathrm{A}}(\mathrm{ml} / \mathrm{min} / \mathrm{mm} \mathrm{Hg})$ & $5.3(0.2)$ & $5.2(0.2)$ & $5.1(0.2)$ & $4.8(0.2)^{* *}$ \\
\hline FVC (litres) & $5.4(0.9)$ & $5.2(0.9)$ & $5.3(0.9)$ & $5.3(1.0)$ \\
\hline $\mathrm{FEV}_{1}$ (litres) & $4.3(0.7)$ & $4.2(0.7)$ & $4.3(0.8)$ & $4.3(0.8)$ \\
\hline $\mathrm{FEF}_{25-75 \%}(\mathrm{l} / \mathrm{s})$ & $4.2(0.3)$ & $4.3(0.3)$ & $4.2(0.3)$ & $4.1(0.3)$ \\
\hline \multicolumn{5}{|l|}{ Gas exchange } \\
\hline $\mathrm{PETO}_{2}(\mathrm{~mm} \mathrm{Hg})$ & $95.8(1.0)$ & $89.1(2.5)$ & $82.9(2.8)^{*}$ & $80.8(3.7)^{*}$ \\
\hline $\mathrm{PETCO}_{2}(\mathrm{~mm} \mathrm{Hg})$ & $36.1(0.9)$ & $33.4(0.7)^{* *}$ & $34.5(1.0)$ & $33.4(0.8)^{*}$ \\
\hline$\dot{\mathrm{V}}_{2}(\mathrm{ml} / \mathrm{min})$ & $431(24.2)$ & $521.5(48.5)$ & $486.4(33.4)$ & $461.5(26.4)$ \\
\hline $\mathrm{V}_{\mathrm{CO}}(\mathrm{ml} / \mathrm{min})$ & $331.3(25.8)$ & $418.8(49.8)$ & $329.6(26.8)$ & $297.6(12.3)$ \\
\hline$R Q$ & $0.77(0.05)$ & $0.8(0.04)$ & $0.68(0.04)$ & $0.66(0.05)$ \\
\hline$\dot{\mathrm{V}}_{2} / \dot{\mathrm{V}}_{\mathrm{A}}$ & $52.6(9.9)$ & $56.2(10.5)$ & $64.0(14.4)^{*}$ & $65.6(14.9)$ \\
\hline $\mathrm{PaO}_{2}(\mathrm{~mm} \mathrm{Hg})$ & $87.8(1.5)$ & $75.9(2.5)^{* \star}$ & $77.3(2.4)^{* *}$ & $69.5(4.1)^{* *}$ \\
\hline $\mathrm{PaCO}_{2}(\mathrm{~mm} \mathrm{Hg})$ & $37.4(0.6)$ & $37.7(0.2)$ & $37.7(0.3)$ & $37.8(0.4)$ \\
\hline $\mathrm{SaO}_{2}(\%)$ & $98.6(0.4)$ & $97.8(0.3)^{*}$ & $97.1(0.5)^{\star *}$ & $97.1(0.6)^{\star \star}$ \\
\hline $\mathrm{A}-\mathrm{aDO}_{2}(\mathrm{~mm} \mathrm{Hg})$ & $8.0(2.0)$ & $13.3(4.5)$ & $5.6(2.8)$ & $11.3(5.2)$ \\
\hline PCV & $0.42(0.3)$ & $0.43(0.05)$ & $0.42(0.04)$ & $0.42(0.05)$ \\
\hline $\mathrm{Hb}(\mathrm{g} / \mathrm{l})$ & $146.20(10.2)$ & $149.30(8.6)$ & $148.70(9.7)$ & $147.10(8.1)$ \\
\hline \multicolumn{5}{|l|}{ Cardiovascular } \\
\hline $\mathrm{SBP}(\mathrm{mm} \mathrm{Hg})$ & $127.4(2.7)$ & $130.8(3.1)$ & $120.9(2.2)$ & $126.4(3.4)$ \\
\hline DBP (mm Hg) & $73.3(3.2)$ & $76.8(4.2)$ & $71.4(2.1)$ & $72.6(2.3)$ \\
\hline MAP (mm Hg) & $91.3(2.37)$ & $94.8(2.55)$ & $87.9(1.5)$ & $90.5(2.1)$ \\
\hline $\mathrm{Cl}\left(1 / \mathrm{min} / \mathrm{m}^{2}\right)$ & $4.1(0.3)$ & $3.4(0.4)^{*}$ & $3.2(0.3)^{* *}$ & $2.8(0.3)^{*}$ \\
\hline $\mathrm{SV}(\mathrm{ml})$ & $113.0(9.7)$ & $117.0(9.2)^{*}$ & $95.4(8.5)$ & $82.5(6.6)$ \\
\hline HR (beats/min) & $75(2.2)$ & $68(4.0)$ & $67.4(2.6)$ & $69.4(4.2)$ \\
\hline $\mathrm{SVR}(\mathrm{mm} \mathrm{Hg} / \mathrm{l} / \mathrm{min})$ & $11.4(1.0)$ & $15.2(2.3)^{*}$ & $15.1(2.3)^{*}$ & $16.5(1.8)^{*}$ \\
\hline
\end{tabular}

Values are mean (SEM)

$\dot{V} E$, Pulmonary ventilation; $\dot{V} A$, alveolar ventilation; $V T$, tidal volume; $\mathfrak{f b}$, respiratory frequency; $V D$, physiological dead space; TLCO, carbon monoxide transfer factor; $\mathrm{VA}_{\text {A }}$ alveolar volume; $\mathrm{FVC}$, forced vital capacity; $\mathrm{FEV}_{1}$, forced expired volume in one second; $\mathrm{FEF}_{25-75 \%}$, forced mid-expiratory flow; $\mathrm{PETO}_{2}$, partial pressure of end tidal $\mathrm{O}_{2} ; \mathrm{PETCO}_{2}$, partial pressure of end tidal $\mathrm{CO}_{2} ; \mathrm{VO}_{2}$, oxygen uptake; $\mathrm{VCO}_{2}$, carbon dioxide output; $\mathrm{RQ}$, respiratory quotient; PaO , arterial partial pressure of $\mathrm{O}_{2} ; \mathrm{PaCO}_{2}$, arterial partial pressure of $\mathrm{CO}_{2} ; \mathrm{SaO}_{2}$, arterial $\mathrm{O}_{2}$ saturation; $\mathrm{A}-\mathrm{aDO}_{2}$, alveolar-arterial $\mathrm{O}_{2}$ tension difference; $\mathrm{PCV}$, packed cell volume; $\mathrm{Hb}$, haemoglobin; SBP, systolic blood pressure; DBP, diastolic blood pressure; MAP, mean arterial pressure; $\mathrm{Cl}$, cardiac index; SV, stroke volume; $\mathrm{HR}$, heart rate; SVR, systemic vascular resistance.

${ }^{*} \mathrm{p}<0.05 ;{ }^{* *} \mathrm{p}<0.01$ compared with baseline (Wilcoxon sign rank test, using Friedman analysis of variance). 

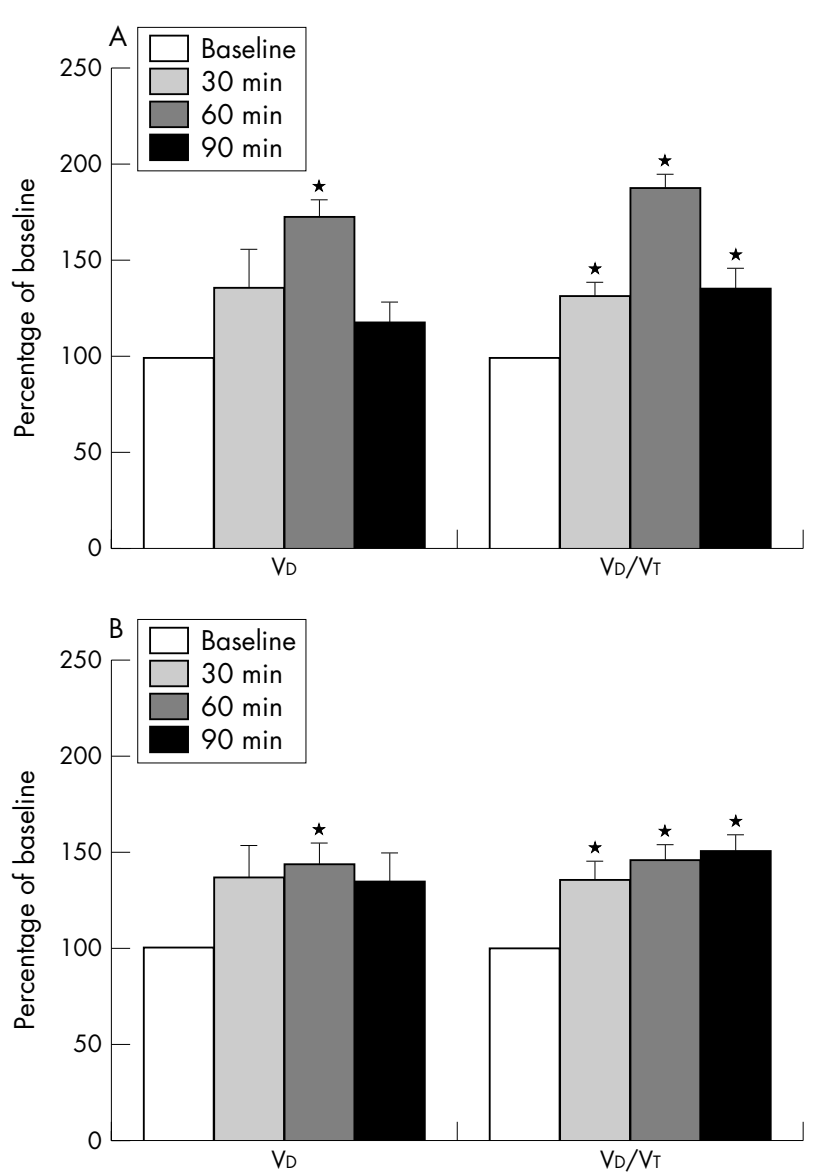

Figure 1 Relative changes in physiological dead space (VD) and the ratio of $V_{D}$ to tidal volume (VT), (VD/VT) 30,60, and 90 minutes after an open sea air dive to $39 \mathrm{~m}$ ( 30 minutes bottom time) in eight divers. Divers were either sitting (A) or lying supine (B) before and after the dive. Values are mean (SEM). *Significantly different from baseline $(p<0.05)$ by Wilcoxon sign rank test, using Friedman analysis of variance.

residual volume of a gas mixture containing $21 \% \mathrm{O}_{2}, 0.3 \%$ $\mathrm{CO}$, and $0.3 \%$ methane balanced with nitrogen. Concentrations of $\mathrm{CO}$ were measured using an infrared analyser (Quark PFT; Cosmed). Each TLCo measurement was examined to ensure that the inspired volume was at least $90 \%$ of the FVC, breath hold time $9-11$ seconds, and the total time of inspiration less than two seconds. ${ }^{12}$ TLCo was adjusted for changes in haemoglobin $(\mathrm{Hb})$ and carboxyhaemoglobin ( $\mathrm{HbCO})$ as follows:

$$
\mathrm{TLCO}_{\text {corr }}=\text { TLCO measured } \times \mathrm{f}(\mathrm{Hb}) \times \mathrm{f}(\mathrm{HbCO})
$$

where $\mathrm{f}(\mathrm{Hb})=(10.22+\mathrm{Hb}) / 1.7 \times \mathrm{Hb}$. This adjusts TLCO to a standard $\mathrm{Hb}$ value of $146 \mathrm{~g} / \mathrm{l}$, as reported by Cotes. ${ }^{13}$ Haemoglobin was measured using a direct reading haemoglobinometer to correct TLCO measurements. Also, $\mathrm{f}(\mathrm{HbCO})$ $=(1.0+\% \mathrm{HbCO}) / 100$ corrects for a rise in $\mathrm{HbCO}$ due to the multiple tests performed. ${ }^{14}$ We were unable to measure $\mathrm{HbCO}$ directly in our subjects, and we used the correction reported by Frey et $a l^{15}$ of $0.71 \%$ rise in $\mathrm{HbCO}$ per test performed. Alveolar volume (VA) was measured by single breath methane dilution, and TLCO/VA was calculated.

\section{Cardiovascular measurements}

During the entire test, heart rate was recorded continuously with a Polar belt (Polar Oy, Kempele, Finland), and arterial blood pressure was measured non-invasively with an auscultatory-oscillometric device (Tango; Sun Tech, Canoga
Park, California, USA). Mean arterial pressure was calculated as $2 / 3$ diastolic blood pressure $+1 / 3$ systolic blood pressure. Pulmonary cardiac output ( $\dot{\mathrm{Q}} \mathrm{t})$ was determined non-invasively (Cosmed Quark b2) by the indirect Fick method, with the $\mathrm{CO}_{2}$ rebreathing technique, from the following equation:

$$
\dot{\mathrm{Q}} \mathrm{t}=\dot{\mathrm{V}} \mathrm{CO}_{2} /\left(\mathrm{C}_{\mathrm{V}} \mathrm{CO}_{2}-\mathrm{CaCO}_{2}\right)
$$

where $\dot{\mathrm{V}} \mathrm{CO}_{2}$ is $\mathrm{CO}_{2}$ output, $\mathrm{C} \overline{\mathrm{V}} \mathrm{CO}_{2}$ is the mixed venous $\mathrm{CO}_{2}$ content, and $\mathrm{CaCO}_{2}$ is the arterial $\mathrm{CO}_{2}$ content. $\dot{\mathrm{V}} \mathrm{CO}_{2}$ was obtained during the last 20 breaths before the rebreathing test. Based on the end tidal $\mathrm{CO}_{2}$ fraction $\left(\mathrm{FeTCO}_{2}\right)$, the $\mathrm{PETCO}_{2}$ was calculated and used to estimate arterial $\mathrm{PCO}_{2}\left(\mathrm{PaCO}_{2}\right)$ according to the formula of Jones et $a l^{16}$ :

$$
\mathrm{PaCO}_{2}(\mathrm{~mm} \mathrm{Hg})=5.5+0.90 \mathrm{PeTCO}_{2}(\mathrm{~mm} \mathrm{Hg})
$$$$
-0.0021 \text { Vт }(\mathrm{ml}) \text {. }
$$

The mixed venous $\mathrm{PCO}_{2}\left(\mathrm{P}_{\overline{\mathrm{v}}} \mathrm{CO}_{2}\right)$ was estimated by the Collier equilibrium method involving rebreathing from a bag containing high $\mathrm{CO}_{2}$ concentration (10\%). ${ }^{17}$ The equilibrium fraction of $\mathrm{CO}_{2}$ was obtained by extrapolation, using the regression line between the 8 and 12 second rebreathing intersect, at 20 seconds after the start of the rebreathing manoeuvre. The equilibrium $\mathrm{CO}_{2}$ pressure was calculated without "downstream" correction. Vanhees et $a l^{18}$ have shown that the equilibrium method is more reproducible than the exponential method for Qt measurements at rest. Qt was measured in duplicate, and the rebreathing bag was thoroughly flushed between two rebreathing periods. Cardiac index (CI) was calculated as Q volume (SV) was calculated as $\mathrm{Q} t / H R$, and systemic vascular resistance (SVR) as mean arterial pressure/Qt.

\section{Statistical analysis}

Data are expressed as mean (SEM). The effect of diving on the variables studied at different times after a dive was evaluated by Friedman analysis of variance. Post hoc comparisons were performed by the Wilcoxon sign rank test. Non-parametric tests were used because of the small sample size $(n=8)$. Posture related effects of diving were evaluated by two way, double repeated measures (post-dive time $x$ post-dive posture) analysis of variance. The effects studied were posture and the interaction between posture and postdive time. This parametric test was used because of its versatility, despite the small sample size, bearing in mind that the test aggregates data from both post-dive postures (unlike in the single dive analyses). To minimise the effect of intersubject variability of baseline values of the studied variables, instead of the raw data, the post-dive changes from baseline values were used in these analyses. Associations between metric variables were evaluated by Pearson's coefficient of correlation. $\mathrm{p}<0.05$ was considered significant. All analyses were carried out using Statistica 6.0 software (Statsoft, Inc, Tulsa, Oklahoma, USA).

\section{RESULTS}

Eight divers completed the study protocol. All divers, as confirmed by inspection of the data downloaded from the diving computer, obeyed the diving schedule. No subjects had clinical signs of decompression sickness, except for one who had minor pain in the right shoulder immediately after the dive. Tables 1 and 2 show cardiopulmonary variables in the sitting and supine posture respectively.

\section{Bubble grade and diving experience}

Venous bubbles were detected in four subjects (two with Spencer's grade I and two with grade II) 30 minutes after diving. In two of these subjects, detectable bubbles persisted 

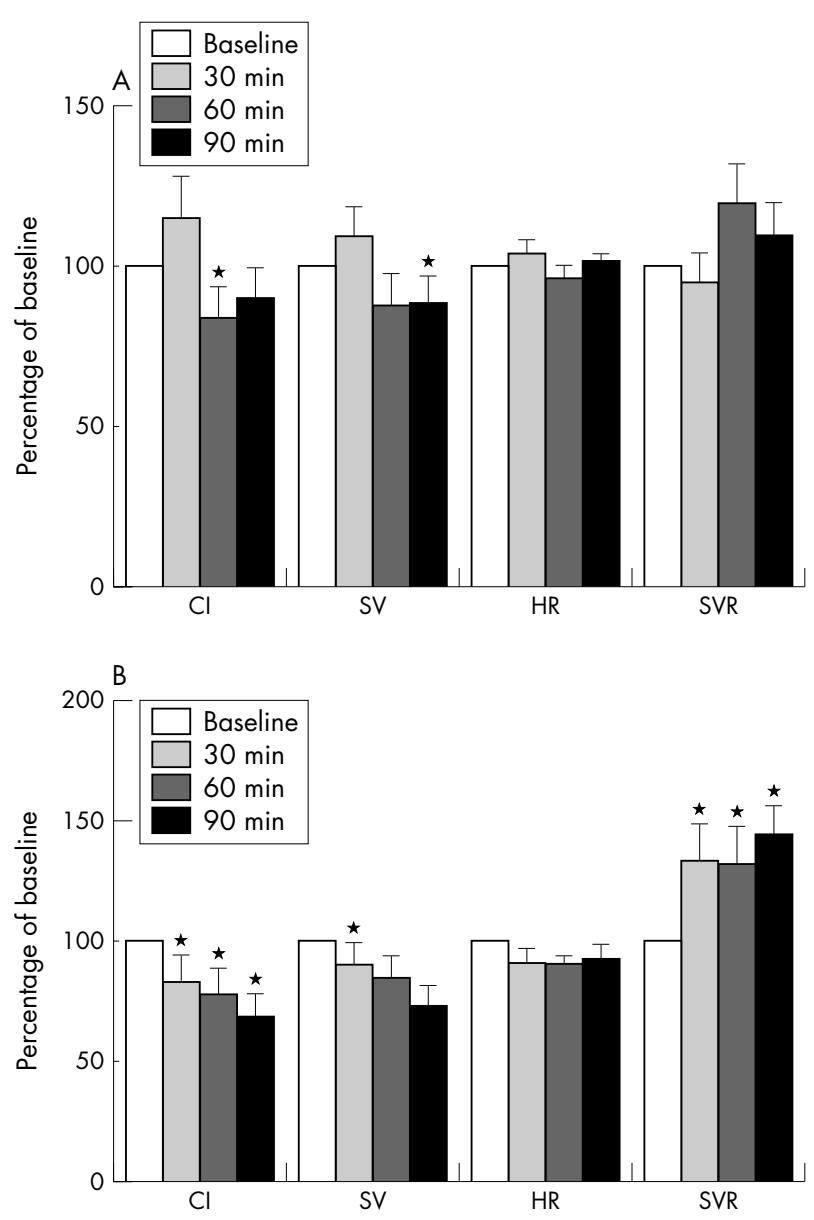

Figure 2 Relative changes in cardiac index (Cl), stroke volume (SV), heart rate (HR), and systemic vascular resistance (SVR) 30, 60, and 90 minutes after an open sea air dive to $39 \mathrm{~m}$ ( 30 minutes bottom time) in eight divers. Divers were either sitting (A) or lying supine (B) before and after the dive. Values are mean (SEM). *Significantly different from baseline $(p<0.05)$ by Wilcoxon sign rank test, using Friedman analysis of variance.

60 minutes after the dive (both with grade 1) in the supine posture. In the latter two divers, bubbles were also detected (both had grade I) 30 minutes after the dive in the sitting posture. In two divers with detectable bubbles on one occasion only (in the supine posture), the presence of bubbles occurred on the first day in one of them and on the second day in the other. In this group of divers, lower bubble grades were observed than in the first study. ${ }^{\prime}$

\section{Dead space}

VD was increased in both positions 60 minutes after the dive, but a larger effect was found in the sitting posture $(73 \% \mathrm{v}$ $44 \%$ ) (figs 1 and 2). VD/VT was increased in both positions at all three post-dive measurements. Anatomical dead space had not changed after the dive.

\section{Spirometric and ventilatory measurements}

There were neither significant nor apparent differences in spirometry and ventilatory measurements before and after the dive (tables 1 and 2).

\section{Diffusing lung capacity}

TLCO and TLCO/VA were significantly reduced after the dive in the supine posture. A biphasic trend was noted in the sitting posture: an initial increase 30 minutes after the dive $(5 \%$, $\mathrm{p}=0.049)$, followed by decreases $60(7 \%, \mathrm{p}=0.011)$ and 90 $(9 \%, p=0.025)$ minutes after the dive. VA was unchanged in both positions after the dive. The changes in TLCO after the dive appeared to depend on posture, but this was not significant $(\mathrm{p}=0.07$, the interaction between posture and time after the dive). TLCo was significantly higher in supine than in seated measurements $(12 \%, \mathrm{p}=0.008$, posture as the main effect in double repeated measures analysis of variance).

\section{Gas exchange}

The respiratory quotient decreased in both postures, mainly because of increased oxygen consumption. Oxygen consumption per unit of alveolar ventilation $\left(\dot{\mathrm{V}}_{2} / \dot{\mathrm{V}}_{\mathrm{A}}\right)$ was even more increased after the dive in both postures. This was associated with reduced $\mathrm{PeTO}_{2}$ despite reductions in $\mathrm{PETCO}_{2} . \mathrm{PaO}_{2}$ and $\mathrm{SaO}_{2}$ were reduced at all times after the dive in both positions, without changes in $\mathrm{A}-\mathrm{aDo}_{2}$ (tables 1 and 2). This suggests that the decrease in arterial oxygen tension after the dive was due to lowered alveolar oxygen tension, which, in turn, resulted from increased $\dot{\mathrm{V}}_{2} / \dot{\mathrm{V}}_{\mathrm{A}}$. For example, $60 \mathrm{~min}$ utes after the dive, when the decrease in $\mathrm{PeTO}_{2}$ was largest, the decreases in $\mathrm{PeTO}_{2}$ (values after the dive - baseline values) correlated with increases in $\dot{\mathrm{V}}_{2} / \dot{\mathrm{V}}_{\mathrm{A}}$ in the supine $(r=-0.89, \mathrm{p}=0.006)$ as well as the sitting $(r=-0.76, \mathrm{p}$ $=0.028$ ) posture. The blood base deficit was increased 30 and 60 minutes after the dive due to a decrease in bicarbonates in both positions (not shown). Diving did not affect packed cell volume or haemoglobin in either posture.

\section{Cardiovascular variables}

CI and SV were reduced significantly 30, 60, and 90 minutes after the dive in the supine posture (table 2, fig 2B), whereas a biphasic trend was noted in the sitting posture: an initial increase 30 minutes after the dive $(15 \%, p=0.036)$, followed by a decrease 60 minutes after the dive (15\%, $\mathrm{p}=0.011$ ) (table 1, fig 2A). Larger reductions in CI and SV were found in the supine position $(p=0.01$ in both cases, interaction of posture and time after the dive in double repeated analysis of variance). Heart rate and mean arterial pressure were not significantly changed. CI was higher for $38 \%$ in the baseline supine posture than in the sitting posture $(p=0.022$, posture as the main effect in double repeated measures analysis of variance) due to an increase in SV $(40 \%)$. SVR was increased significantly only in the supine position 30,60, and 90 minutes after the dive (fig 2B). For each diver, the time to equilibrium of $\mathrm{CO}_{2}$ pressure was practically the same before and after the dive, which is important for reproducibility of measurements of CI by the rebreathing method.

There were no apparent differences in baseline variables or response to the dive between the two smokers and six nonsmokers.

\section{DISCUSSION}

We have shown acute depression in lung respiratory function and cardiac output after open sea field dives. There have been similar findings with dry diving, but this is the first report on the effect of diving on cardiac output in humans. Although an increase in physiological dead space was measured in most of the divers, venous bubbles were detected by precordial Doppler in only some of them. Thus, either the changes observed were caused by factors other than VGM or the Doppler method is too insensitive and the changes were caused by non-detectable bubbles.

\section{Study limitations}

We have not performed control dives, which would have enabled correction for factors other than VGM associated 
with the dive. These could have been performed by prolonged or oxygen decompression (as we had used in the previous study). Thus, within the limits of this study, it is not possible to isolate the effects of venous bubbles from the effects of submersion and respiratory mechanical load during the dive. We have used non-invasive cardiopulmonary measurements, which might have produced inaccurate estimates of some of the variables. However, in assessing changes with respect to the baseline pre-dive condition, reproducibility of measurement is the major concern. One may question the reproducibility of measurement of cardiac output after a dive by the rebreathing method when lung and heart function are affected. However, for each diver, the time to equilibrium of $\mathrm{CO}_{2}$ pressure between alveoli and mixed venous blood did not differ before and after the dive. This argues against a significant impact of diving on measuring cardiac output by the rebreathing technique. Arterialised capillary blood and oximetry may be influenced by cold exposure during diving, causing peripheral vasoconstriction. This could produce bias in comparing values obtained before and after diving. However, if this effect of diving on the measurements did exist, it would probably have materialised immediately after diving, not 60 and 90 minutes after it, when the measured decreases in arterial oxygen saturation and tension were the greatest.

\section{Posture after the dive}

The posture of the diver after the dive may be important. However, different bubble grades were measured in different postures in the same divers after apparently the same dives. This lack of reproducibility in the production of venous inert gas bubbles after the dive makes it difficult to compare the sitting with the supine posture. For example, it may be that more bubbles and not posture caused a greater decrease in cardiac output in the supine posture. Furthermore, the effects of submersion and increased breathing resistance cause central pooling of blood and fluid shifts. During the recovery phase after the dive, these effects may last longer if the diver is lying down than when sitting upright. Thus it is not clear in this study whether posture had an effect or not, and, if so, whether it was primary or secondary.

\section{Diffusion and arterial gases}

This wet dive study replicated the findings of decreased lung diffusing capacity after a dry dive. ${ }^{12}$ The reasons behind these findings remain unclear. One may relate a decrease in Tuco to a parallel build up of alveolar dead space after a dive. However, in dogs, using $0.3 \%$ of CO in inspired gas (as in a standard single-breath TLCO measurement), Chappel et al ${ }^{19}$ have shown that the CO uptake in the stagnant blood pool distal to the occlusion is not stopped, but only slightly slowed down (due to a build up of the back pressure and partial collapse of the occluded vessels). Bearing this in mind and the small part of the lung occluded, it is unlikely that the increased dead space accounted for the observed decrease in TLCo. The previously observed correlation between bubble grade and percentage decrease in Tuco after a dry dive ${ }^{1}$ was not replicated in the present study. TLCo has also been reported to decrease after exercise of different durations and intensities ${ }^{20}$ and these restrictions may last up to six hours. ${ }^{21}$ A reduction in both pulmonary capillary blood volume and membrane TLCO component have been reported. The former was reduced only after 10 minutes of cycling at $25 \%$ of maximal $\dot{\mathrm{V}}_{2}{ }_{2}{ }^{22}$ As the open sea dive represents mild to moderate exercise, this mechanism of acute TLCO reduction has to be considered. However, the argument against this possibility is that even greater decreases in TLCO were reported in dry dives, when divers were sedentary. Lastly, Thorsen et $a l^{23}$ reported similar effects on TLCO after immersion of subjects and negative pressure breathing. In that study as well as in this one, there was central pooling of blood resulting from immersion and increased breathing resistance. This may have caused increased pulmonary capillary transmural pressure, leading to accumulation of fluid in the interstitium and reduction of gas transfer in the lungs. Negative static lung loading (lower pressure at the mouth compared with the lung centroid) during ascent in the upright posture produces effects similar to negative pressure breathing, ${ }^{24}$ contributing to interstitial engorgement. Regardless of the mechanism responsible for the decrease in TLCO, the more relevant question is whether or not it could have been responsible for the decrease in $\mathrm{PaO}_{2}$. It has been predicted on a theoretical basis and confirmed experimentally that TLCO must be reduced below $50 \%$ to limit $\mathrm{O}_{2}$ alveolo-capillary equilibration. ${ }^{25}$ Therefore it is not likely that a TLCO reduction of $9 \%$ contributed significantly to the $20 \%$ reduction in $\mathrm{PaO}_{2}$ in the present study. Moreover, most of this reduction in arterial oxygen tension is explained by the decrease in alveolar oxygen tension. A decrease in alveolar oxygen tension was observed in parallel with increased oxygen consumption per unit of alveolar ventilation. One may speculate that hyperoxia during diving causes a metabolic shift from carbohydrate towards lipid metabolism and that this effect persists for some time after a dive.

\section{Cardiac output and blood pressure}

This is the first study to report changes in cardiovascular function after a single open sea air dive in humans. Reductions in cardiac output after the dive were due to decreased SV, in the presence of increased SVR and unchanged arterial blood pressures. We observed significantly increased SVR only in the supine posture (up to $45 \%$, 90 minutes after the dive), although the same trend was noted in the sitting posture. Changes in cardiovascular variables observed in this study are consistent with experiments in dogs and pigs. ${ }^{26}{ }^{27}$ In animal models, the decreases in cardiac output after the dive were related to decreased venous return and increased afterload of the right and (or) left ventricle (due to increased positive airway pressure and SVR respectively). ${ }^{26-29}$ However, these results can hardly be extrapolated to human diving, because of great differences in bubble load and possible species differences. For example, significant VGM created by hypobaric exposure in astronauts did not result in increased positive airway pressure, suggesting greater lung clearance capacity in humans. ${ }^{30}$ Theoretically, decreased venous return may be due to decreased plasma volume (caused by diving induced diuresis and exercise induced plasma extravasation) or an exercise induced shift of blood from the central circulation to periphery. The small, non-significant changes in packed cell volume and haemoglobin argue against plasma reduction after the dive in our study. Still, relatively small changes in plasma volume may have profound haemodynamic effects, and the power of our study to detect such changes in packed cell volume or haemoglobin was rather small. Peripheral blood pooling has been reported after maximal and submaximal exercise to increase the clearance of metabolic waste products from exercised muscles. ${ }^{31}$ This effect was independent of the body position. ${ }^{32}$ During field dives in our study, divers did no defined exercise, but the open sea dive represents mild to moderate exercise depending on the sea currents, temperature, stress, etc, in comparison with the chamber dive. The fact that divers did some level of exercise is evident from the reduction in arterialised bicarbonate of about $2 \mathrm{mmol}$ and increased blood base deficit. In any case, the similar pattern of changes in TLCO and cardiac output after the dive suggests a common underlying cause. 


\section{What is already known on this topic}

Dry and wet (open sea) dives are associated with hyperoxia, increased density of breathing gas, and decompression stress with possible formation of venous bubbles and subsequent lung microembolisation.

In conclusion, the field dive was followed by acute, moderate deterioration in pulmonary gas exchange and cardiac output. These changes were detected in parallel with a slightly increased physiological dead space in most of the divers and the presence of venous bubbles in only a few of them. The lowered arterial oxygen tension was explained by increased oxygen consumption per unit of alveolar ventilation, whereas the mechanisms of other effects of diving remained unclear. Posture after the dive may have influenced some of these observations, but neither profoundly or consistently.

\section{ACKNOWLEDGEMENTS}

We thank Miss Sandra Dujić-Bilušić, Mrs Jolanda Zloković, and Dr Vladimir Ivančev for their technical assistance. We acknowledge the contribution of two anonymous reviewers whose criticism contributed much to the presentation of this article. This study was financially supported by the Croatian National Council for Research grant No 0216006. All the procedures conducted in the experiment comply with the current laws of Croatia.

\section{Authors' affiliations}

Z Dujic, D Bakovic, I Marinovic-Terzic, D Eterovic, School of Medicine, University of Split, Split, Croatia

Competing interests: none declared

\section{REFERENCES}

1 Dujic Z, Eterovic D, Denoble $P$, et al. Effect of a single air dive on pulmonary diffusing capacity in professional divers. J Appl Physiol 1993;74:55-61.

2 Thorsen E, Risberg J, Segadal K, et al. Effects of venous gas microemboli on pulmonary gas transfer function. Undersea Hyperb Med 1995;22:347-53.

3 Tetzlaff K, Friege L, Koch A, et al. Effects of cold and depth on lung function after a single scuba dive. Eur J Appl Physiol 2001;85:125-9.

4 Cotes JE, Davey IS, Reed JW, et al. Respiratory effects of a single saturation dive to $300 \mathrm{~m}$. Br J Ind Med 1987;44:76-82.

5 Suzuki S, Ikeda T, Hashimoto A. Decrease in the single-breath diffusing capacity after saturation dives. Undersea Biomed Res 1991;18:103-9.

6 Thorsen E, Segadal K, Kamberstad BK. Mechanisms of reduced pulmonary function after a saturation dive. Eur Respir J 1994;7:4-10

7 Thorsen E, Kambestad BK. Persistent small-airways dysfunction after exposure to hyperoxia. J Appl Physiol 1995;78:1421-4.

8 Skogstad M, Thorsen E, Haldorsen T, et al. Divers' pulmonary function after open-sea bounce dives to 10 and 50 meters. Undersea Hyperb Med 1996;23:71-5

9 Souders JE, Doshier JB, Polissar NY, et al. Spatial distribution of venous gas emboli in the lungs. J Appl Physiol 1999;87:1937-47.

10 Spencer MP. Decompression limits for compressed air determined by ultrasonically detected blood bubbles. J Appl Physiol 1976;40:229-35
What this study adds

Open sea dives are associated with moderate impairments in cardiac output and gas exchange. Some of these impairments appear to depend on the posture of the diver after the dive.

11 American Thoracic Society. Standardization of spirometry, 1994 update. Am J Respir Crit Care Med 1995; 152:1107-36.

12 American Thoracic Society. Single-breath carbon monoxide diffusing capacity. Am J Respir Crit Care Med 1995;152:2185-98.

13 Cotes JE. Lung function, 4th ed. London: Blackwell, 1979:246.

14 Mohsenifar Y, Tashkin DP. Effects of carboxyhemoglobin on the single breath diffusing capacity: derivation of an empirical correction factor. Respiration 1979:37:185-91.

15 Frey TM, Crapo RO, Jensen RL, et al. Diurnal variation of the diffusing capacity of the lung: is it real? Am Rev Respir Dis 1987;136:1381-4.

16 Jones NL, Robertson DG, Kane JW. Difference between end-tidal and arterial $\mathrm{PCO}_{2}$ in exercise. J Appl Physiol 1979;47:954-60.

17 Collier CR. Determination of mixed venous $\mathrm{CO}_{2}$ tensions by rebreathing. J Appl Physiol 1956;9:25-9.

18 Vanhees L, Defoor J, Schepers D, et al. Comparison of cardiac output measured with two automated methods of $\mathrm{CO}_{2}$ rebreathing. Med Sci Sports Exerc 2000;32:1028-32.

19 Chappel TR, Cassidy SS, Schwiep F, et al. Quantification of pulmonary vascular occlusion in dogs by use of the diffusing capacity. J Appl Physiol 1988:64:1229-38.

20 Manier G, Moinard J, Stoicheff $\mathrm{H}$. Pulmonary diffusing capacity after maximal exercise. J Appl Physiol 1993;75:2580-5.

21 Petroianu G, Heil P, Jatzko A, et al. Isovolemic fluid replacement during venous air embolism (VAE). Undersea Hyperbaric Medical Society 1997; (suppl 24):23.

22 Rasmussen J, Hanel B, Saunamaki K, et al. Recovery of pulmonary diffusing capacity after maximal exercise. J Sports Sci 1992;10:525-31.

23 Thorsen E, Skogskad M, Reed JW. Subacute effects of inspiratory loading and head-out water immersion on pulmonary function. Undersea Hyperb Med 1999;26:137-42.

24 Camporesi EM, Bosco G. Ventilation, gas exchange and exercise under pressure. In: Brubakk AO, Neuman TS, eds. Bennett and Elliott's physiology and medicine of diving, 5th ed. 2003:104-7.

25 Johnson RL, Taylor HF, DeGraff AC. Functional significance of a low pulmonary diffusing capacity for CO. J Clin Invest 1965;44:789-800.

26 Bove AA, Hallenbeck JM, Elliott DH. Circulatory responses to venous air embolism and decompression sickness in dogs. Undersea Biomed Res 1974; 1:207-20.

27 Vik A, Brubakk AO, Hennessy TR, et al. Venous air embolism in swine: transport of gas bubbles through the pulmonary circulation. J Appl Physiol 1990;69:237-44.

28 Butler BD, Robinson R, Little T, et al. Cardiopulmonary changes with moderate decompression in rats. Undersea Hyperb Med 1996;23:83-9.

29 Nishi RY. Doppler evaluation of decompression tables. In: Lin YC, Shida KK, eds. Man in the sea. San Pedro, CA: Best Publishing Company, 1990:297-316.

30 Diesel DA, Ryles MT, Pilmanis AA, et al. Non-invasive measurement of pulmonary artery pressure in humans with simulated altitude-induced venous gas emboli. Aviat Space Environ Med 2002;73:128-33.

31 Hanel B, Teunissen I, Rabol A, et al. Restricted postexercise pulmonary diffusing capacity and central blood volume depletion. J Appl Physiol 1997:83:11-17.

32 Stewart IB, Potts JE, McKenzie DC, et al. Effect of body position on measurements of diffusing capacity after exercise. Br J Sports Med 2000;34:440-4. 